\title{
Determination of Flavonoid and Polyphenol Compounds in Viscum Album and Allium Sativum Extracts
}

\author{
Svetlana Trifunschi ${ }^{1},{ }^{*}$ Melania Florina Munteanu ${ }^{1}$, Vlad Agotici ${ }^{1}$, Simona Pintea (Ardelean) ${ }^{1}$ and Ramona Gligor ${ }^{2}$ \\ ${ }^{1}$ Department of Pharmaceutical Science,"Vasile Goldis" Western University of Arad, Arad, Romania \\ 2Department of General Medicine,"Vasile Goldis" Western University of Arad, Arad, Romania
}

\begin{abstract}
Ethnopharmacology is a new interdisciplinary science that appeared in Europe of the '90, in France, as a necessity claimed by the return to the traditional remedies of each nation. The aim of this study is to identify and quantify the active ingredients of the species Viscum album and Allium sativum, in order to provide a complex chemical characterisation, which is necessary for the use of these plants' extracts as natural ingredients in the pharmaceutical industry. The following methods were used: (1) the plant material was harvested from the west-side of Romania (Europe) in July 2014; (2) it was dried quickly and the main active principles were extracted using ethylic alcohol solution (50\%); (3) the quantitative analyses of the flavonoids and polyphenols were performed according to a procedure described in the Romanian Pharmacopoeia. FT-IR results showed that the Viscum album extract had the highest content of polyphenolic compounds, for both flavonoids and polyphenols. This is the reason why it can be concluded that alcoholic extracts of mistletoe must be used as supplements for diabetics who require diets with flavonoids or for patients with cancers, degenerative diseases, and particularly cardiovascular diseases, who need an increased amount of polyphenols.
\end{abstract}

Key Words: garlic, mistletoe, rutin, catechol, cinarin, FTIR.

\section{INTRODUCTION}

The mistletoe (Viscum album), belonging to the Loranthaceaeeste family, is a semiparazit herbaceous plant, which grows on the stems of the host plant, having the appearance of branchy bushes, with stems reaching a length that varies between 30 and $100 \mathrm{~cm}$, thickened at nodes, where it breaks easily. The leaves are arranged in opposite pairs, the flowers have yellow-greenish coloration, while the fruits are hyaline, with many seeds, green in the incipient stage of development and whitish when reaching maturity. The fruits usually appear from October to December. This plant parasites the birch, the fir, the ash, the rose, the apple and the wild pear trees. The young branches with leaves are used for pharmaceutical purposes. Harvesting is possible all year round, however specialists recommend the cold season for this activity. Its most important chemical compounds are: triterpenic saponins, flavonoids, acetylcholine, viscin, viscitoxin, mineral substances, amino acids, C, E vitamins and mucilage (Bujor, 2003; Vicas et al., 2009; Zuber, 2004).

The garlic (Allium sativum), belonging to the Liliaceae family, is a plant which has been grown for more than 5000 years for both culinary and therapeutic purposes. The part used for its medicinal properties is the bulb, which is formed of several cloves, wrapped in individual membrane. Its best known chemical compound is allicin, which has an extensive pharmacological action. The allicin has hypotensive, antimicrobial, antitumoral and immunomodulatory properties (Thomas and Ali, 2003; Bayan et al., 2014).

Having as starting point the present knowledge, the aim of the article hereby is to provide a qualitative and quantitative characterization of the flavonoid content of the two plants.

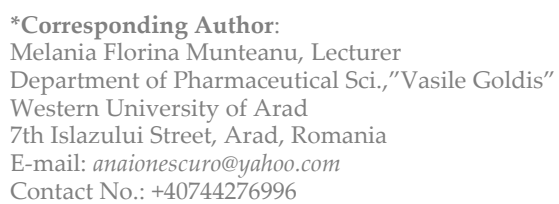

\section{MATERIALS AND METHODS}

\section{Plant material}

The plant material used for extraction consisted of leaves of Viscum album, which parasite the pear tree and homegrown bulbs of Alium sativum. The plants were harvested from Groseni village (Arad County, Romania) in July 2014. The harvested material was dried quickly at a temperature of $90^{\circ} \mathrm{C}$, for 48 hours. It was deposited under the shade, at a temperature of $20^{\circ} \mathrm{C}$ (Markham, 1982; Meriga et al., 2012).

\section{Reagents}

Rutin and catechol, used as standard samples, were purchased from Sigma-Aldrich. All the other reagents used for this research were at analytical grade purity.

\section{Plant extraction}

In order to obtain the alcohol extract, $1 \mathrm{~g}$ plant material (Viscum album and Allium sativum), was pulverized and subjected to extraction with $100 \mathrm{~mL}$ ethylic alcohol (50\%), under reflux on a water bath for 30 minutes. The boiling solution was filtered through cotton in a graded flask, and after cooling down it was completed to $100 \mathrm{~mL}$, by washing the residue with the same solvent (solution A EV1, EU1).

\section{Determination of flavonoids content}

The quantitative analysis of the flavonoids was performed according to the method presented in the Romanian Pharmacopoeia (F.R. X, 1993), using ethanol rutin as the standard substance.

$10 \mathrm{~mL}$ solution A was diluted with methanol (R) to $25 \mathrm{~mL}$ in a graded flask. After stirring, the solution was rested for 10 minutes. Afterwards, the solution was filtered, removing the first fractions of the filtrate. $0.5 \mathrm{~mL}$ filtrate was mixed with $5 \mathrm{~mL}$ of sodium acetate $100 \mathrm{~g} / \mathrm{L}(\mathrm{R})$ and $3 \mathrm{~mL}$ of aluminium chloride $25 \mathrm{~g} / \mathrm{L}$; after a preliminary stirring it was enriched with methanol (R) to $25 \mathrm{~mL}$, in a graded flask (sample solution). After 15 minutes, it was enriched once more with methanol (R) to $25 \mathrm{~mL}$ and 
the absorption of the solution was determined at $430 \mathrm{~nm}$, by using a solution which had been obtained under similar circumstances as the sample solution as compensation liquid. The new solution was obtained from $5 \mathrm{~mL}$ filtrate, $8 \mathrm{~mL}$ water and methanol $(\mathrm{R})$ to $25 \mathrm{~mL}$, in a graded flask.

The flavonoids content of the extracts was determined from the standard calibration curve for rutin, and it was expressed in rutin equivalents or $\mathrm{mg}$ rutin $/ \mathrm{mL}$ extract. The standard calibration curve for rutin was obtained by using a rutin solution, having a concentration that varied between 0.01 and $0.07 \mathrm{mg}$ rutin $/ \mathrm{mL}$.

\section{Determination of polyphenols content}

The quantitative analysis of the polyphenols was made using as standard substance, the piro-catechol, cinarin respectively (F.R. X, 1993) and the standard reactive (R) as they are presented in Pharmacopoeia.

The research was carried out with the same plant material, which was presented in the previous paragraphs.

In order to obtain the alcoholic extract, $1 \mathrm{~g}$ plant material was subjected to extraction with $100 \mathrm{~mL}$ ethylic alcohol (50\%), under reflux on water bath for 30 minutes. The boiling solution was filtered through cotton in a graded flask, and after cooling down it was completed to $100 \mathrm{~mL}$ by washing the residue with the same solvent (solution A - EV1, EV2).

\section{Determination of total polyphenols content}

$5.0 \mathrm{~mL}$ solution A was added to $5 \mathrm{~mL}$ of phosphotungstic acid, solution (R). After stirring, it was filtered, thus removing the first fractions of the filtrate. Then, $5.0 \mathrm{~mL}$ filtrate was diluted with sodium carbonate (R) $200 \mathrm{~g} / \mathrm{l}$ for $10 \mathrm{~mL}$, in a graded flask (sample solution). After 1 minute, the absorption of the solution was determined at $660 \mathrm{~nm}$, by using a solution, which was made of $0.5 \mathrm{~mL}$ of filtrate and brought with water to $10 \mathrm{~mL}$, in a graded flask, as compensation liquid.

The content of polyphenol compounds of the extracts was determined by using the standard calibration curve for catechol, and it was expressed in $\mathrm{mg}$ cate$\mathrm{chol} / \mathrm{mL}$ extract. The standard calibration curve was obtained by using a solution with a concentration varying between 0.001 and $0.005 \mathrm{mg} / \mathrm{mL}$ catechol.

Identification of flavonoid debris by FTIR spectroscopy The FTIR spectra for the extracts were determined with a Spectrum Two FTIR Spectrometer (Perkin Elmer). The FTIR spectroscopy highlighted valance vibrations $\vee \mathrm{C}=\mathrm{O}$, through strips having between 1630 and $1665 \mathrm{~cm}^{-1}$, which are typical for the flavonoids structure; valance vibrations $v$ C-O through strips having between 1000 and $1300 \mathrm{~cm}^{-1}$, and in-plane deformation vibrations, $\delta \mathrm{C}-\mathrm{H}$ through strips having between 600 and $980 \mathrm{~cm}^{-1}$.

\section{Compliance with ethics requirements}

Authors declare that they have no conflict of interest and there were not any procedures involving animal or human subjects in this research.

\section{RESULTS AND DISCUSSION}

\section{Determination of flavonoids content}

The flavonoids content of the Viscum album and Allium sativum extracts was expressed as rutin equivalent (standard equation of the curve: $y=0.626 x+0.024 ; R^{2}=$ $0.933)$, as it can be seen in table 1 .
The calibration curve for rutin is shown in figure 1 , and the flavonoids content for each plant material analysed in this study is shown in table 1.

The flavonoid content for Viscum album extract is equal to $0.4245 \mathrm{mg}$ rutin $/ \mathrm{mL}$ extract, and for Allium satioum extract is equal to $0.1823 \mathrm{mg}$ rutin $/ \mathrm{mL}$. The highest flavonoids content was identified in the Viscum album extract.

Table 1: Total flavonoid content expressed in rutin.

\begin{tabular}{cccc}
\hline Extract & $\begin{array}{c}\text { Absorption, } \\
\mathbf{4 3 0} \mathbf{~ n m}\end{array}$ & $\begin{array}{c}\text { Concentration } \\
\text { mg rutin/mL } \\
\text { extract }\end{array}$ & $\begin{array}{c}\text { Flavonoids g\% } \\
\text { (rutin, \%) }\end{array}$ \\
\hline EV1 & 0.389 & 0.4245 & 1.6980 \\
EU1 & 0.167 & 0.1823 & 0.7292 \\
\hline
\end{tabular}

Table 2: Polyphenols content of the pirochatechina type of the analysed extracts.

\begin{tabular}{cccc}
\hline Extract & $\begin{array}{c}\text { Absorption, } \\
\mathbf{6 6 0} \mathbf{~ n m}\end{array}$ & $\begin{array}{c}\text { Total polyphe- } \\
\text { nols content } \\
\text { (mg catechol) }\end{array}$ & $\begin{array}{c}\text { \%Polyphenol } \\
\text { compounds }\end{array}$ \\
\hline EV1 & 0.989 & 0.0475 & 23.75 \\
EU1 & 0.665 & 0.0336 & 16.80 \\
\hline
\end{tabular}

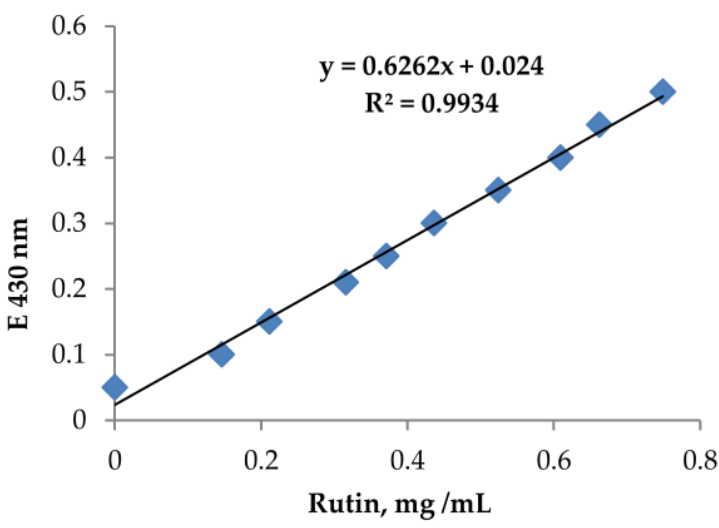

Figure 1: Standard calibration curve for rutin.

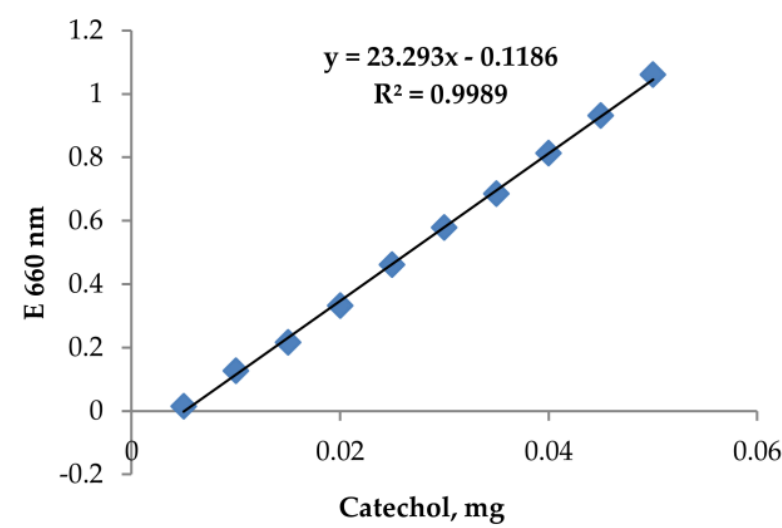

Figure 2: Calibration curve for catechol. 


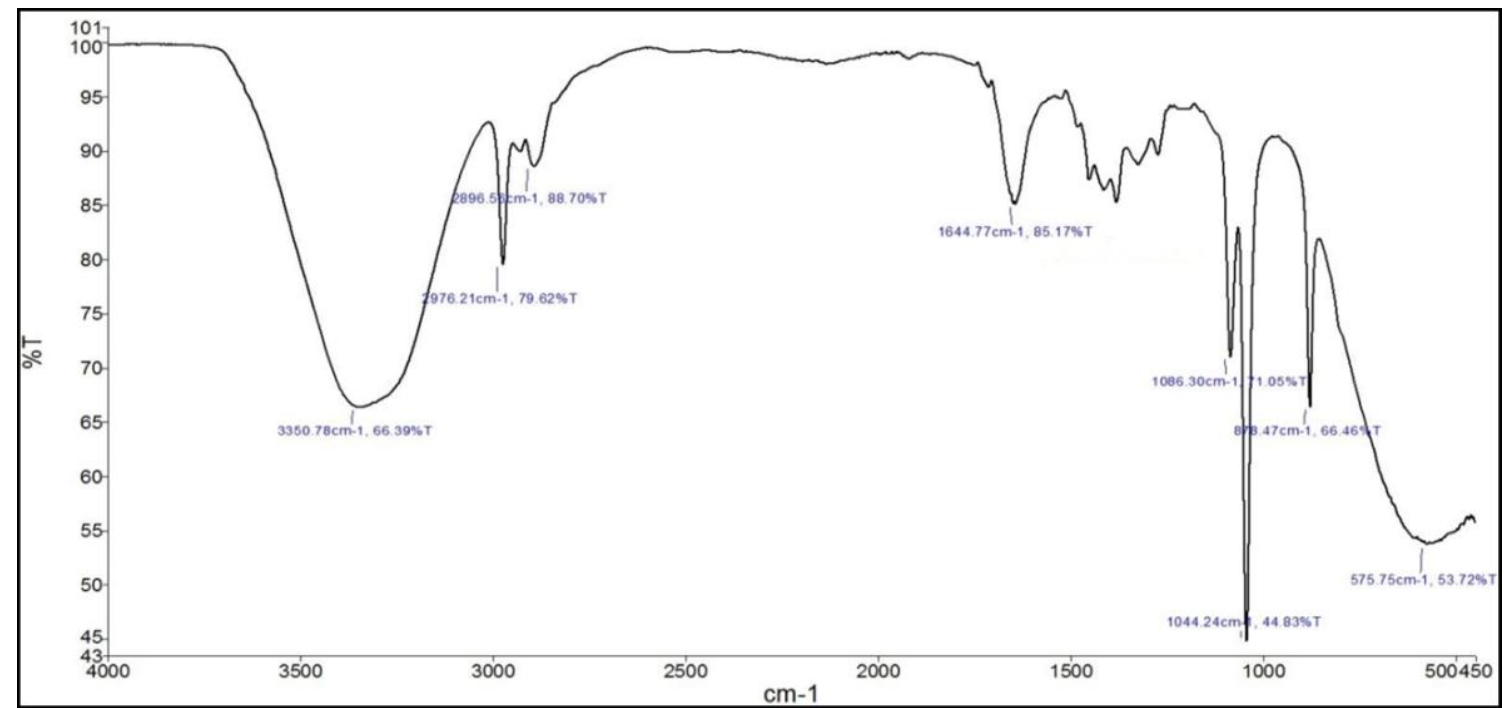

Figure 3: FTIR Spectrum for the Viscum album extract (EV1).

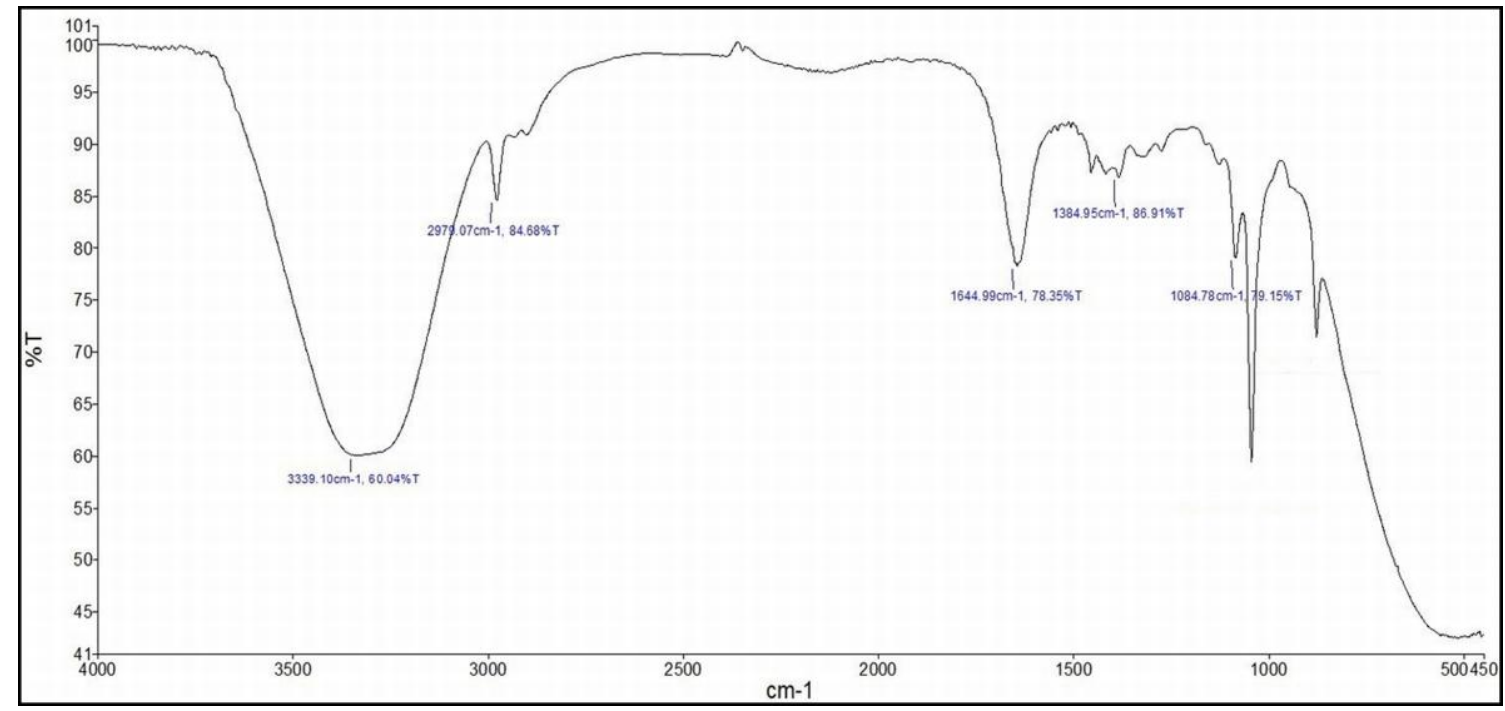

Figure 4: The FTIR Spectrum for the Allium sativum extract (EU1).

\section{Determination of polyphenols content}

The polyphenols content was expressed as catechol equivalent (standard equation of a line: $\mathrm{y}=23.29 \mathrm{x}-0.018$; $\mathrm{R}^{2}=0.998$ ). The calibration curve obtained for catechol is shown in figure 2, and polyphenols content obtained for each extract is shown in table 2 .

The polyphenols content for Viscum album extract is equal to $0.0475 \mathrm{mg}$ catechol $/ \mathrm{mL}$ extract, and for the Allium sativum extract is equal to $0.0336 \mathrm{mg}$ catechol $/ \mathrm{mL}$. The highest content of polyphenol compounds was identified in the Viscum album extract.

\section{Identification of flavonoid debris with the FTIR spectroscopy}

The FTIR spectrum for the Viscum album extract (EV1) (figure 3) shows the following characteristic peaks: $3200 \mathrm{~cm}^{-1} ; 2986 \mathrm{~cm}^{-1} ; 2896 \mathrm{~cm}^{-1} ; 1644 \mathrm{~cm}^{-1} ; 1384 \mathrm{~cm}^{-1} ; 1086 \mathrm{~cm}^{-1}$; $1044 \mathrm{~cm}^{-1} ; 877 \mathrm{~cm}^{-1} ; 575 \mathrm{~cm}^{-1}$ respectively. The $3300 \mathrm{~cm}^{-1}$, $2970 \mathrm{~cm}^{-1}$ and $2856 \mathrm{~cm}^{-1}$ peaks are specific to the $\mathrm{OH}$ group and to the $\mathrm{CH}_{2}$ symmetric frequency $\left(\mathrm{CH}_{2}\right.$ stretching frequency). The peak having the value of $1644 \mathrm{~cm}^{-1}$ represents the $C=C$ relation; $1384 \mathrm{~cm}^{-1}$ peak corresponds to the $\mathrm{OH}$ phenolic group; the $1086 \mathrm{~cm}^{-1}$ peak corresponds to the $\mathrm{C}-\mathrm{H}$ relation, which is specific for the aromatic nucleus; the $1044 \mathrm{~cm}^{-1}$ peak corresponds to the ketone group, while 878 and $575 \mathrm{~cm}^{-1}$ peaks correspond to the inplan deformation vibrations, $\delta \mathrm{C}-\mathrm{H}$.

The FTIR Spectrum for Alium sativum (EU1) (figure 4) shows the following characteristic peaks: $3339 \mathrm{~cm}^{-1}$; $2979 \mathrm{~cm}^{-1} ; 1644 \mathrm{~cm}^{-1} ; 1384 \mathrm{~cm}^{-1} ; 1084 \mathrm{~cm}^{-1} ; 1044 \mathrm{~cm}^{-1}$ and $877 \mathrm{~cm}^{-1}$ respectively. The $3339 \mathrm{~cm}^{-1}$ and $2979 \mathrm{~cm}^{-1}$ peaks are specific for $\mathrm{OH}$ group and for the $\mathrm{CH}_{2}$ symmetric frequency $\left(\mathrm{CH}_{2}\right.$ stretching frequency). The peaks having the value of $1644 \mathrm{~cm}^{-1}$ represents the $\mathrm{C}=\mathrm{C}$ relation; the $1384 \mathrm{~cm}^{-1}$ peak corresponds to the $\mathrm{OH}$ phenolic group; the $1084 \mathrm{~cm}^{-1}$ peak to the C-H relation, which is characteristic for the aromatic nucleus; the $1044 \mathrm{~cm}^{-1}$ peak corresponds to the ketone group, while the $878 \mathrm{~cm}^{-1}$ peak corresponds to the in-plan deformation vibrations, $\delta \mathrm{C}-\mathrm{H}$. 


\section{CONCLUSION}

The presence of flavonoids and polyphenols in the two species was studied both qualitatively through IR spectroscopy, and quantitatively (quantitative dosage) by using the spectroscopy method. The IR spectroscopy highlighted valence vibrations $\mathrm{C}=\mathrm{O}$, through strips between 1630 and $1665 \mathrm{~cm}^{-1}$, typical for the flavonoids structure; valence vibrations $\mathrm{C}-\mathrm{O}$, through strips between 1000 and $1350 \mathrm{~cm}^{-1}$ and in-plan deformation vibrations, C$\mathrm{H}$, through strips between 600 and $980 \mathrm{~cm}^{-1}$. The flavonoids content was determined quantitatively, for the plant material subjected to study and it had values between 0.73 and 1.70 (\% rutin) for the Viscum album extracts. Cathecol type polyphenols (catechol) of the plant material were dosed quantitatively. The research pointed out a content of cathecol type polyphenols of approximately 16.4$23.75 \%$. The Viscum album extract had the highest content of polyphenolic compounds, for both flavonoids and polyphenols.

\section{ACKNOWLEDGEMENT}

This work was financially supported by "Vasile Goldis" Western University of Arad, internal competition grant (contract no. Pi5/21.07.2014).

\section{REFERENCES}

Bayan, L., Koulivand, P.H., Gorji, A. (2014) Garlic: a review of potential therapeutic effects. Avicenna Journal Phytomed, Volume 4, Issue 1 Pages 1-14.

Bujor, O. (2003) Ghidul plantelor medicinale si aromatice de la A la Z. Editura Fiat Lux, pp. 232.

Markham, K.R. (1982) Techniques of flavonoid identification, Academic Press, pp. 15.

Meriga, B., Mopuri, R., MuraliKrishna, T. (2012) Insecticidal, antimicrobial and antioxidant activities of bulb extracts of Allium sativum. Asian Pacific Journal Trop Medicine, Volume 5, Issue 5, Pages 391-395. [DOI]

Romanian Pharmacopoeia X (1993).

Thomson, M., Ali M. (2003) Garlic [Allium sativum]: a review of its potential use as an anti-cancer agent. Current Cancer Drug Targets, Volume 3, Issue 1, Pages 67-81. [DOI]

Vicas, S.I., Rugina, D., Pantea, S., Socaciu, C. (2009) The Morphological Features and UV-VIS Analysis of Some Taxonomic Markers of Genus Viscum. Bulletin UASMV Agriculture, Volume 66, Issue 1, Pages 193 200

Zuber D. (2004) Biological flora of Central Europe: Viscum album L. FloraMorphology, Distribution, Functional Ecology of Plants, Volume 199, Pages 181-203. [DOI] 